\title{
Clustering and aggregations of minke whales in the Antarctic feeding grounds
}

\author{
Fujio Kasamatsu $^{1, *}$, Paul Ensor ${ }^{2}$, Gerald G. Joyce ${ }^{3}$ \\ ${ }^{1}$ Marine Ecology Research Institute, 3-29 Jinbo-cho, Kanda, Chiyoda, Tokyo 101-0051, Japan \\ ${ }^{2}$ Governor's Bay, Lyttelton RD1, New Zealand \\ ${ }^{3}$ Moon Joyce Resources, 11740 Exeter Avenue, N.E., Seattle, Washington 98115, USA
}

\begin{abstract}
Information on the degree of clustering and aggregation behavior of whales is extremely limited. To obtain such information within various survey areas would not only be of help in understanding cetacean ecology, but also in optimizing the survey design in order to obtain abundance estimates with minimal variance. The clustering and aggregation patterns of minke whales Balaenoptera acutorostrata were examined using the data derived from systematic sighting surveys in 3 major feeding grounds in Antarctic waters. Distribution patterns showed that minke whales clustered in the Antarctic feeding grounds but were relatively randomly distributed within the aggregations, with the possibility that schools within the aggregation tend to avoid each other Higher clustering was observed in areas within bays (Ross Sea and Prydz Bay) than in areas of open water (Weddell Sea). Mean school sizes were positively correlated with density. Aggregation patterns in relation to density and abundance in Antarctic waters are presented.
\end{abstract}

KEY WORDS: Minke whale Distribution Aggregation C Clustering - Antarctic - Ross Sea - Weddell Sea $\cdot$ Prydz Bay $\cdot$ Sighting survey

\section{INTRODUCTION}

The spatial distribution of whales is of interest for a number of reasons. The degree of clustering is of independent biological interest, with respect to the behavior. The effort required to examine these micro-distribution patterns and the driving forces behind them would be amply rewarded not only by gaining a greater understanding of cetacean ecology but also by leading to improvment in the design of censusing methods to obtain abundance estimates with minimal variance, since variability depends on the degree of clustering. The spatial distribution of cetaceans in Antarctic waters has been previously presented (Kasamatsu et al. 1988, 1995, 1996, 1998, Kasamatsu \& Joyce 1995). Their results, however, dealt only with the large-scale patterns of distribution. Our understanding of the distribution patterns or aggregation patterns of cetaceans is very limited when compared with studies of terrestrial animals such as insects or birds (Mac-

·E-mail: fkasamat@mxm.meshnet.or.jp
Arthur 1955, 1972, Mangel \& Clark 1988). This limitation is due - at least in part - to the difficulties of studying pelagic populations.

To look at the small-scale distribution patterns and degree of clustering, we utilized a technique more common in terrestrial studies, in which we divided the study area into uniformly-sized quadrats and then examined and compared the contents of each sampling unit. In this study we used a fairly large number of units and were interested in the density of minke whales in each unit. To provide adequate sample sizes, we limited the study to the southern minke whale Balaenoptera acutorostrata, because it was the target species of these surveys and also because the minke whale is an important part of the Antarctic marine ecosystem. To examine areas where a distribution pattern might be the most detectable, we limited the study to geographic regions of the Antarctic survey where minke whales had been observed with relatively high frequency, that is, portions of the southern Ross Sea, the Weddell Sea, and Prydz Bay. The southern Ross Sea is a large bay environment, the Prydz Bay region is 
a small bay environment, and the Weddell Sea is an offshore environment. In addition to looking at the gross distribution patterns, we also examined the mean density of schools within aggregations, the dimensions of aggregations, patchiness as a function of contagious distribution, and crowding.

\section{MATERIALS AND METHODS}

Sighting surveys and data. The data were collected on the International Whaling Commission/International Decade of Cetacean Research (IWC/IDCR) Southern Hemisphere Minke Whale Assessment Cruises (IDCR cruises) (Best \& Ohsumi 1980, Kasamatsu et al. 1988). The sighting surveys were conducted mainly aboard 3 Japanese research vessels, with an additional ship from the former Soviet Union used primarily for ice reconnaissance. All ships were converted whale catchers ( 750 to 900 gross tons), which used trained personnel to locate and identify whales. The vessels traveled along pre-planned tracklines in 1 of 2 search-effort modes: closing mode and passing mode. In closing mode, the ship diverted its course and accelerated to 15 knots to approach the sighted school or whale in order to identify the species and to count all the whales in the school. In these surveys, the definition of a school is based on interindividual distance and behavior. A school was recognized when the inter-individual distance was less than a few whale body lengths and the whales exhibited the same behavior. In passing mode, the vessel navigated along the trackline without diverting or changing speed, and all species identification and number estimates were made from the trackline. The tracklines of the surveys were designed systematically to provide unbiased information on the density of whales in the research areas. Complete details of the cruises are found in Best \& Butterworth (1980), Anonymous (1987, 1988), Kasamatsu et al. (1988, 1996), Kasamatsu et al. (1989), and Kasamatsu \& Joyce (1995). We have looked at a subset of the collected data, focusing on areas identified as having a high incidence of minke whales. Compared with other survey areas, very high densities of minke whales were reported in the southern part of the Ross Sea, the Weddell Sea, and Prydz Bay during the IDCR cruises. Data from the cruises in 1985/86 (Ross Sea), the 1986/87 (Weddell Sea), and the 1988/89 (Prydz Bay), were used. The cruise tracks for these areas are shown later in Figs. 2, 3 \& 4.

Estimation of the number of minke whales. The number of minke whale schools in each 4 nautical mile (n mile) long sampling unit on the trackline (Fig. 1) was estimated from the sightings data using a line transect method (Burnham et al. 1980, Hiby \& Hammond 1989 , Buckland et al. 1993). The following equation was used:

$$
\widehat{N_{i}}=\frac{n_{i} A \hat{f(0)}}{2 L_{i}}
$$

where $\widehat{N}_{1}$ is the number of schools in $i$ th sampling unit; $n_{i}$ is the number of schools seen $A$ is the area of the unit; $L_{i}$ is the distance searched ( $4 \mathrm{n}$ miles); and $f(0)$ is the estimated probability density of perpendicular distances, evaluated at zero distance, calculated from fitting the Hazard rate model (Buckland 1985), $1 / f(0)$ is the effective search half-width.

Most studies of distribution patterns (especially for terrestrial animals) are likely to be based on a series of randomly placed quadrat samples in a given area. In the Antarctic surveys presented here, sampling was systematic rather than random. Since the tracklines of the surveys were located to ensure neither over-nor under-sampling in high-or low-density areas, the surveys provide unbiased information about the distribution pattern of whales in the research areas.

Index of clustering and mean crowding. The dispersion pattern of an animal is derived by dividing the variance of animal density $V$ by the mean density $m$ (Taylor 1961, Pielou 1969). This index (V/m) can be used to examine whether the distribution is random $(V / m=1$, following the Poisson distribution), uniform $(V / m<1)$ or clustering (or contagious) $(V / m>1)$, while this index may not be a good indicator of the extent of clustering or aggregation.

The pattern revealed is usually patchy, with areas of high and low density not corresponding to any obvious differences in habitat. In such a distribution, the major ity of individuals find themselves in a local patch of relatively high density, in close proximity to many more individuals of their own species than would be expected if the distribution were random. In this sense, a typical individual is more crowded than it would be if it were in an area where the distribution was random but had the same mean density. Mean density, therefore, is misleading as a measure of crowding. In addition,

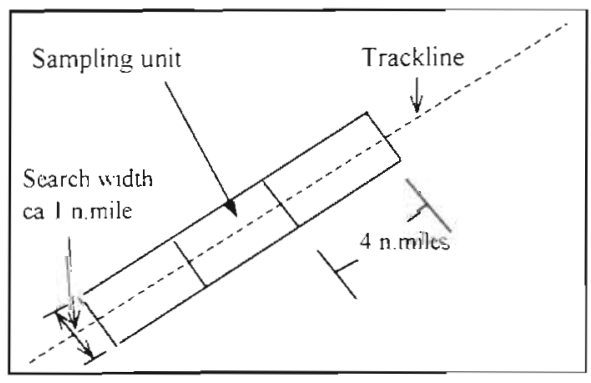

Fig. 1. Sampling units and trackline 


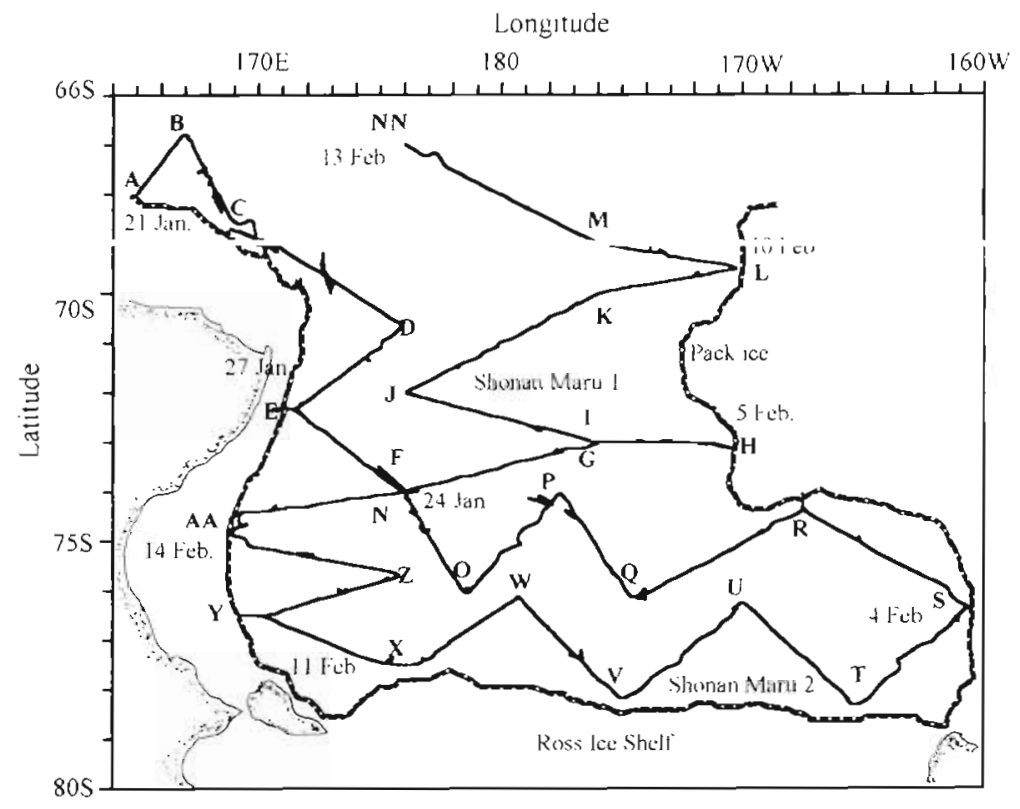

Fig. 2. Cruise tracks and waypoints sampled on the 1985/86 cruise in the southern Ross Sea

southeast (NSE, Waypoints N-S), and southern southeast (SSE, Waypoints $\mathrm{S}-\mathrm{X}$ ) Weddell Sea: northwest (NW, Waypoints A-C), northeast (NE, Waypoints C-E), middle west (MW, Waypoints $F-K$ ), middle east (ME, Waypoints $\mathrm{K}-\mathrm{O}$ ), southwest ( $\mathrm{SW}$, Waypoints P-S), and southeast (SE, Waypoints $\mathrm{S}-\mathrm{U}$ ). Prydz Bay was treated as 1 stratum (Figs. 2, 3 \& 4).

\section{RESULTS}

\section{Distribution and aggregations of minke whales}

The distributions of minke whale schools along the tracklines in the southern Ross Sea, the Weddell Sea, and Prydz Bay are shown in Figs. 5, 6 \& 7. These figures reveal variations in the spatial occurrence of minke whales not only in density but also in continuation (length) of the occurrence. The frequency distributions of minke

because the index $\mathrm{V} / \mathrm{m}$ is affected by the level of mean density, we also calculated the Morishita's index $\left(I_{\delta}\right)$ (Morishita 1959) to examine the degree of clustering:

$$
I_{\delta}=\frac{n \sum\left[x_{i}\left(x_{i}-1\right)\right]}{N(N-1)}
$$

where $n$ is number of units; $x_{i}$ is number of schools in the $i$ th unit; and $N$ is total number of schools. Lloyd (1969) also proposed the use of $m^{*}$ (mean crowding, the mean number per individual of other individuals in the same quadrat) to describe the clustering of animals. We calculated mean crowding using the equation:

$$
m^{*}=\frac{\sum x_{i}\left(x_{i}-1\right)}{\sum x_{i}}=\frac{\sum x_{i}^{2}}{\sum x_{i}}-1
$$

Lloyd (1969) mentioned that mean crowding would be meaningful only when the population is loosely aggregated and the quadrat size is not too large compared with the size of the 'ambit' for individuals of the species concerned. Empirically, a population of whales falls within this criterion.

To facilitate the analysis, the collected data were post-stratified by north-south and east-west strata (associated with the tracklines) as follows. Ross Sea: northwest (NW, Waypoints A-D), middle west (MW, Waypoints D-F), southwest (SW, Waypoints $\mathrm{X}-\mathrm{N}$ ), northeast (NE, Waypoints $\mathrm{K}-\mathrm{N}$ ), middle east (ME, Waypoints $F-K$ ), northern

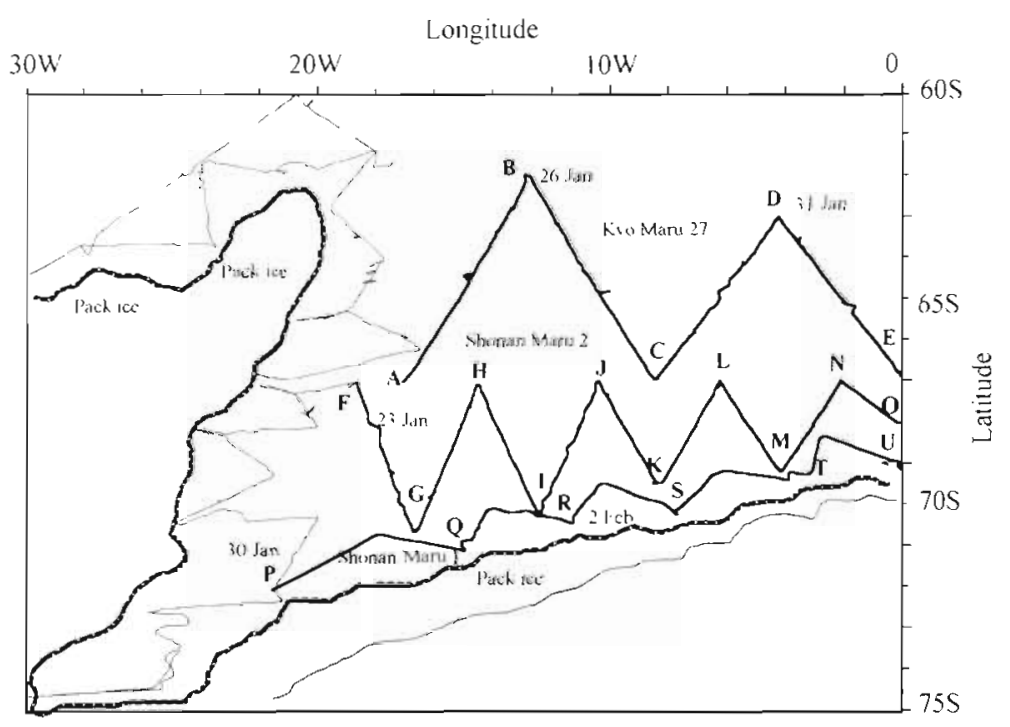

Fig. 3. Cruise tracks and waypoints sampled on the $1986 / 87$ cruise in the Weddell Sea. Bold lines show the trackline examined 


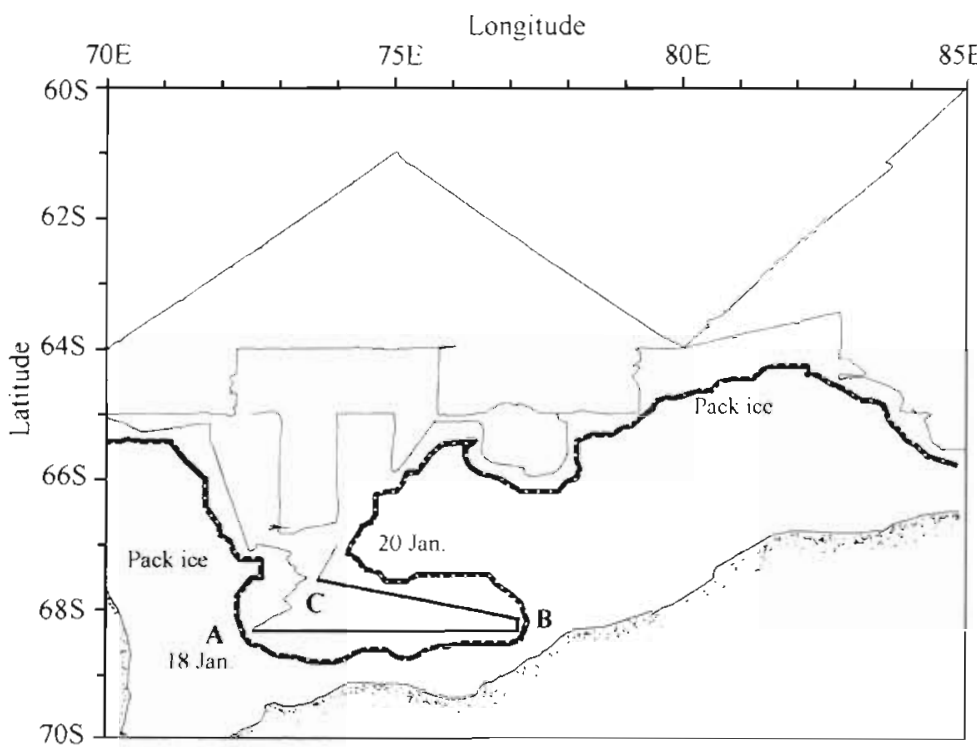

Fig. 4. Cruise tracks and waypoints sampled on the 1988/89 cruise in Prydz Bay. Bold lines show the trackline examined whales. Definition of an aggregation is a problem. Loosely defined, an aggregation was considered to occur in areas containing a continuous relatively high density of whales. We arbitrarily defined the area of an aggregation to be where the density is more than 3 times the mean density observed in the southern strata of the Antarctic waters and where the length of the area is more than 3 times the average length of the areas in which whales occurred. Seven aggregations were observed in the Ross Sea (numerals I to VII in Fig. 5). The mean school density per unit in these aggregations ranged from 2.3 to 4.2 schools with a mean of 2.7 schools. The lengths of these aggregations were from 30 to $100 \mathrm{n}$ miles (Table 2, Fig. 5). In the Weddell Sea, 3 aggregations were observed (numerals VIII to $\mathrm{X}$, Fig. 6). The mean

Table 1. Mean density, index of clustering, and mean crowding of minke whales in the southern Ross Sea, the Weddell Sea and Prydz Bay. WP: waypoints; $m$ : mean; $V$ variance; whole: whole area

\begin{tabular}{|c|c|c|c|c|c|c|}
\hline Area & WP & Strata & $\begin{array}{c}\text { Mean } \\
\text { density }(m)\end{array}$ & $\begin{array}{c}\text { Index of } \\
\text { clustering }(\mathrm{V} / \mathrm{m})\end{array}$ & $\begin{array}{l}\text { Morishita's } \\
\text { index }\left(I_{\delta}\right)^{a}\end{array}$ & $\begin{array}{c}\text { Mean } \\
\text { crowding }\left(m^{*}\right)^{\mathrm{b}}\end{array}$ \\
\hline Ross Sea & $\begin{array}{l}\text { Whole } \\
\text { A-D } \\
D-F \\
F-K \\
K-N \\
N-S \\
S-X \\
X-N\end{array}$ & $\begin{array}{l}\text { NW } \\
\text { MW } \\
\text { ME } \\
\text { NE } \\
\text { NSE } \\
\text { SSE } \\
\text { SW }\end{array}$ & $\begin{array}{l}0.77 \\
0.24 \\
1.72 \\
0.65 \\
0.41 \\
0.59 \\
1.46 \\
0.67\end{array}$ & $\begin{array}{l}2.93 \\
1.32 \\
2.76 \\
1.90 \\
2.11 \\
2.15 \\
3.47 \\
2.16\end{array}$ & $\begin{array}{l}3.51 \\
2.36 \\
2.03 \\
2.38 \\
3.75 \\
2.98 \\
2.70 \\
2.76\end{array}$ & $\begin{array}{l}2.70 \\
0.55 \\
3.46 \\
1.53 \\
1.51 \\
1.73 \\
3.91 \\
1.83\end{array}$ \\
\hline Weddell Sea & $\begin{array}{l}\text { Whole } \\
\text { A-C } \\
\text { C--E } \\
\text { F-K } \\
\text { K-O } \\
\text { P-S } \\
\text { S-U }\end{array}$ & $\begin{array}{l}\text { NW } \\
\text { NE } \\
\text { MW } \\
\text { ME } \\
\text { SW } \\
\text { SE }\end{array}$ & $\begin{array}{l}0.42 \\
0.48 \\
0.66 \\
0.36 \\
0.42 \\
0.49 \\
0.08\end{array}$ & $\begin{array}{l}1.82 \\
1.33 \\
3.85 \\
0.91 \\
1.56 \\
1.24 \\
1.27\end{array}$ & $\begin{array}{l}2.95 \\
1.69 \\
5.32 \\
0.75 \\
2.36 \\
1.50 \\
5.00\end{array}$ & $\begin{array}{l}1.23 \\
0.80 \\
3.48 \\
0.27 \\
0.96 \\
0.72 \\
0.33\end{array}$ \\
\hline Prydz Bay & Whole & & 1.05 & 2.75 & 2.67 & 2.76 \\
\hline
\end{tabular}

Table 2. Mean density, index of clustering, and mean crowding of minke whales in the aggregations, and length of aggregations

\begin{tabular}{|c|c|c|c|c|c|c|c|}
\hline Area & WP & $\begin{array}{l}\text { Aggreg. } \\
\text { ID }\end{array}$ & $\begin{array}{c}\text { Mean } \\
\text { density }(m)\end{array}$ & $\begin{array}{l}\text { Length } \\
\text { (n miles) }\end{array}$ & $\begin{array}{c}\text { Index of } \\
\text { clustering }(V / m)\end{array}$ & $\begin{array}{l}\text { Morishita's } \\
\text { index }\left(I_{\delta}\right)\end{array}$ & $\begin{array}{c}\text { Mean } \\
\text { crowding }\left(m^{\circ}\right)\end{array}$ \\
\hline Ross Sea & $\begin{array}{l}E-F \\
E-F \\
F-G \\
M-N \\
T-U \\
T-U \\
Z-A A\end{array}$ & $\begin{array}{c}\text { I } \\
\text { II } \\
\text { III } \\
\text { IV } \\
\text { V } \\
\text { VI } \\
\text { VII }\end{array}$ & $\begin{array}{l}2.92 \\
4.15 \\
3.00 \\
2.33 \\
2.90 \\
3.07 \\
2.67\end{array}$ & $\begin{array}{r}49 \\
56 \\
55 \\
30 \\
32 \\
100 \\
39\end{array}$ & $\begin{array}{l}1.90 \\
1.12 \\
0.89 \\
0.80 \\
1.41 \\
2.25 \\
0.84\end{array}$ & $\begin{array}{l}1.29 \\
1.03 \\
0.97 \\
0.92 \\
1.13 \\
1.40 \\
0.95\end{array}$ & $\begin{array}{l}3.66 \\
4.19 \\
2.76 \\
2.00 \\
3.17 \\
4.24 \\
2.42\end{array}$ \\
\hline Weddell Sea & $\begin{array}{l}B-C \\
C-D \\
M-N\end{array}$ & $\begin{array}{l}\text { VIII } \\
\text { IX } \\
X\end{array}$ & $\begin{array}{l}2.29 \\
3.50 \\
2.83\end{array}$ & $\begin{array}{l}28 \\
66 \\
27\end{array}$ & $\begin{array}{l}0.25 \\
1.80 \\
0.62\end{array}$ & $\begin{array}{l}0.70 \\
1.21 \\
0.88\end{array}$ & $\begin{array}{l}1.50 \\
4.07 \\
2.35\end{array}$ \\
\hline Prydz Bay & $\mathrm{B}-\mathrm{C}$ & XI & 3.13 & 60 & 1.27 & 1.08 & 3.32 \\
\hline
\end{tabular}



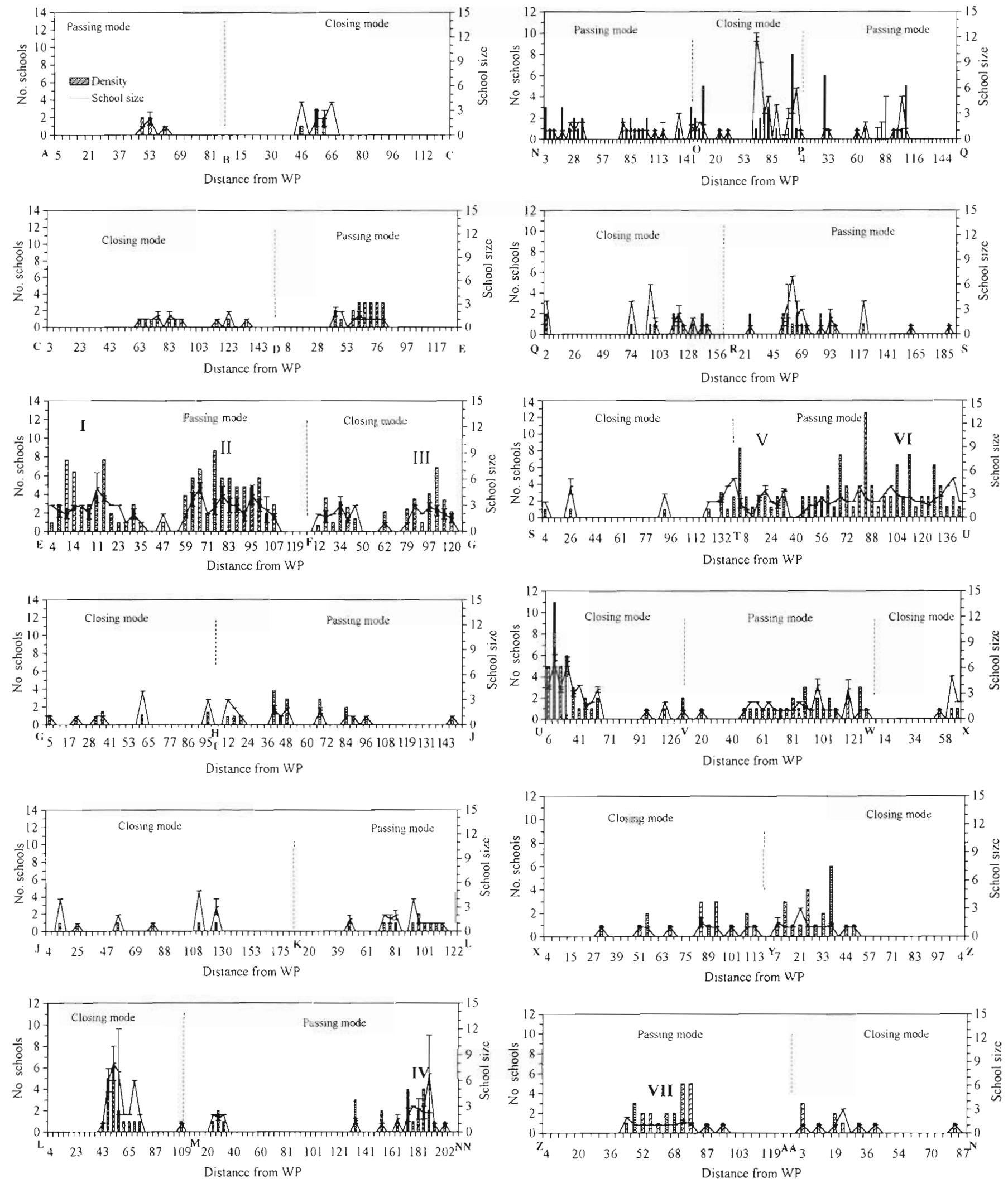

Fig. 5. Minke whale school density in the southern part of Ross Sea. Roman numerals are ID numbers of the aggregations WP: waypoint 

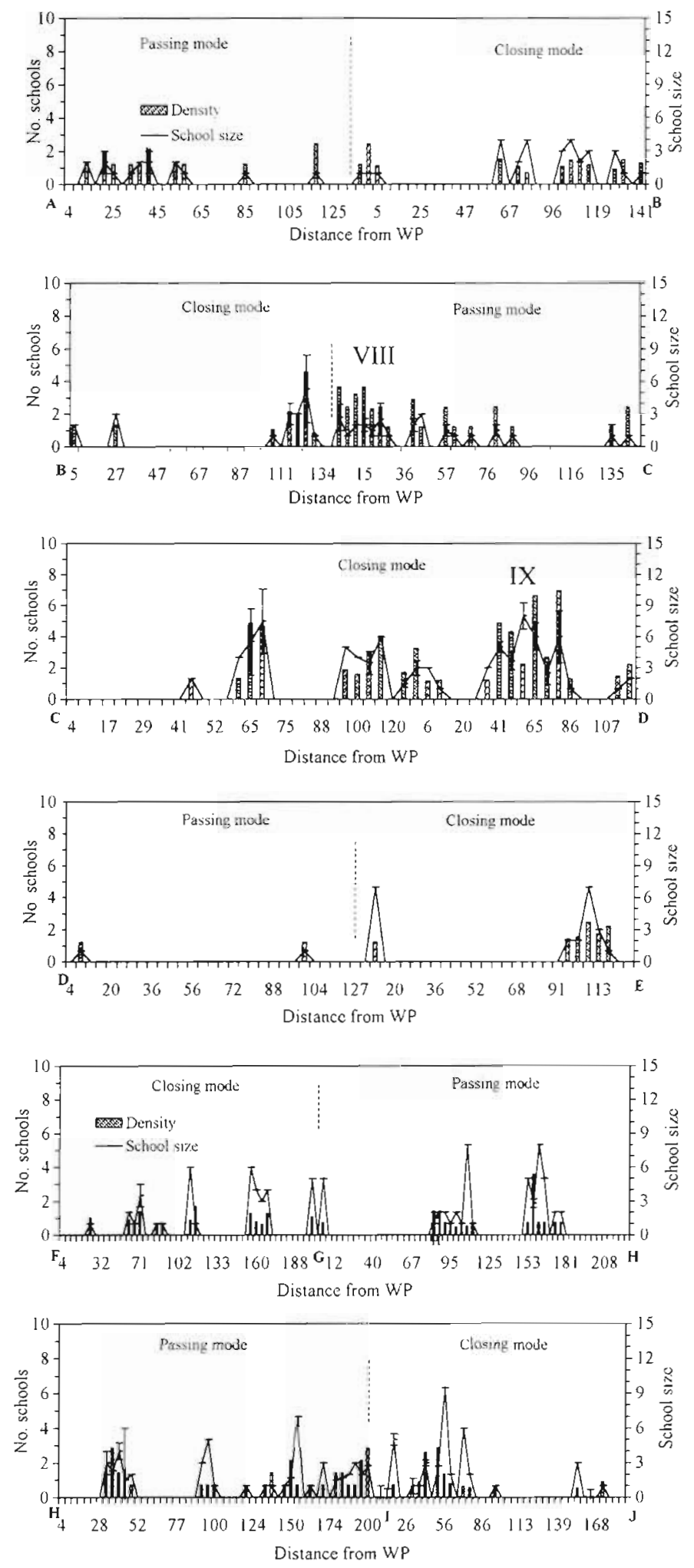

school density per unit in these aggregations ranged from 2.3 to 3.5 with a mean of 2.8 schools. Similar mean densities were observed in aggregations in the Ross Sea area (Table 2). The lengths of Weddell Sea aggre-

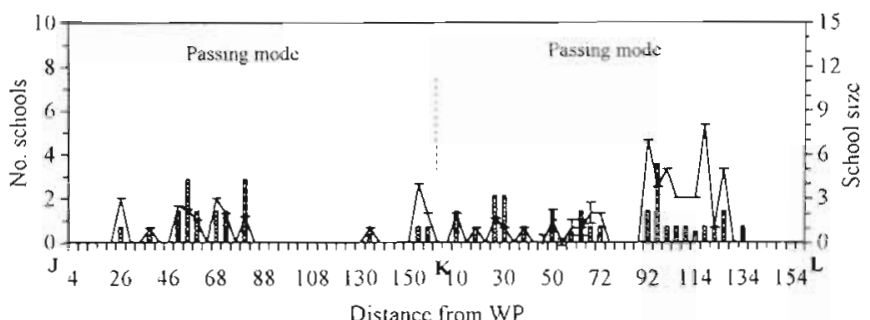

Distance from WP
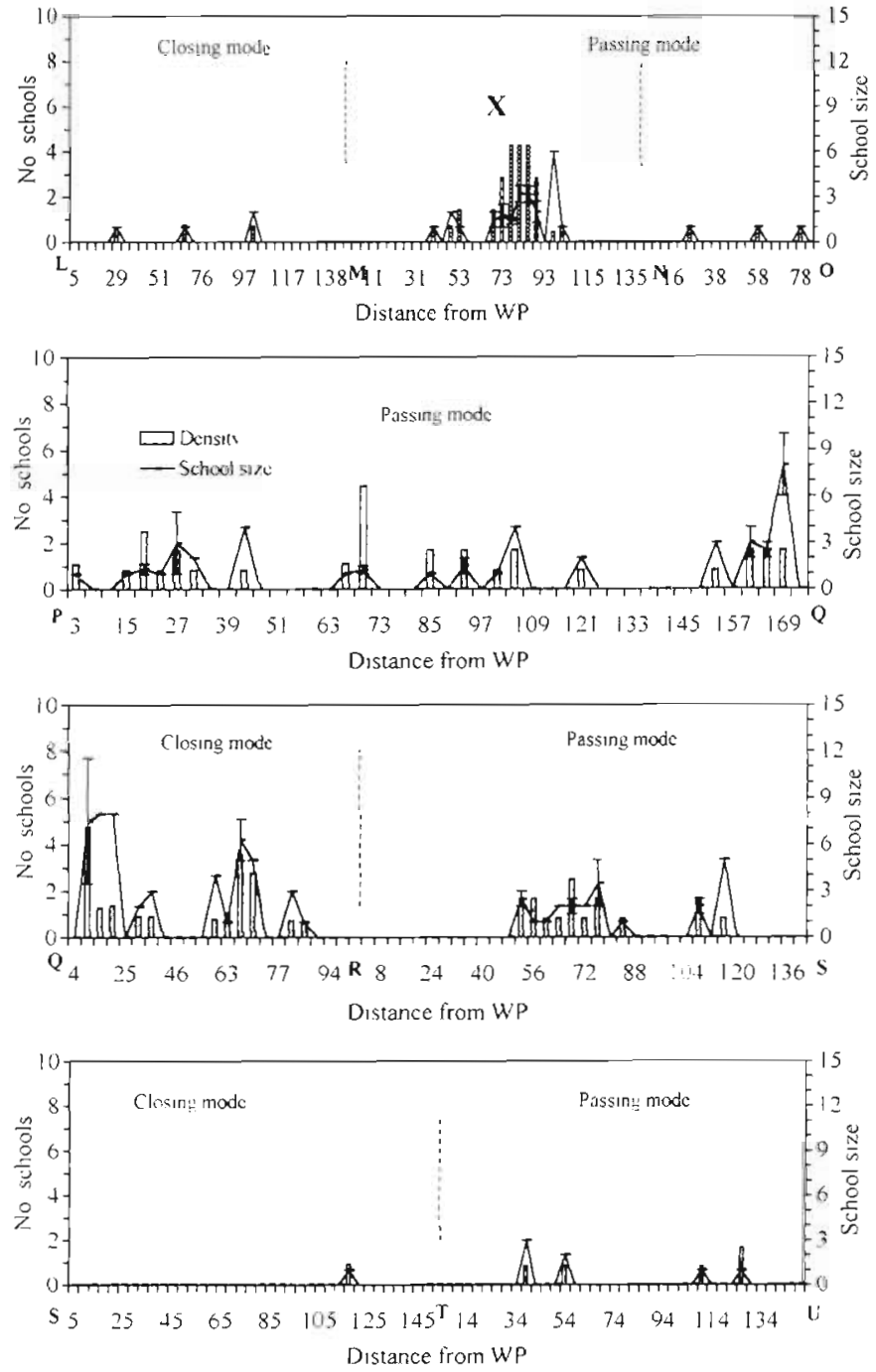

Fig. 6. Minke whale school density in the Weddell Sea. Roman numerals are ID numbers of the aggregations. WP: waypoint

gations were 27,28 , and $66 \mathrm{n}$ miles, respectively. In Prydz Bay, a single aggregation was observed (numeral $X_{i}$ Fig. 7). Mean school density per unit was 3.13 schools with a length of $60 \mathrm{n}$ miles.

Figs. $8 \mathrm{~b}, 9 \mathrm{~b} \& 10 \mathrm{~b}$ show that within the aggregations the frequency distributions were different to those observed over the whole transect (Figs. 8a, 9a \& 10a). The distributions are not significant different from a Poisson distribution (chi-squared: 11.87, 3.82, and 5.59; 

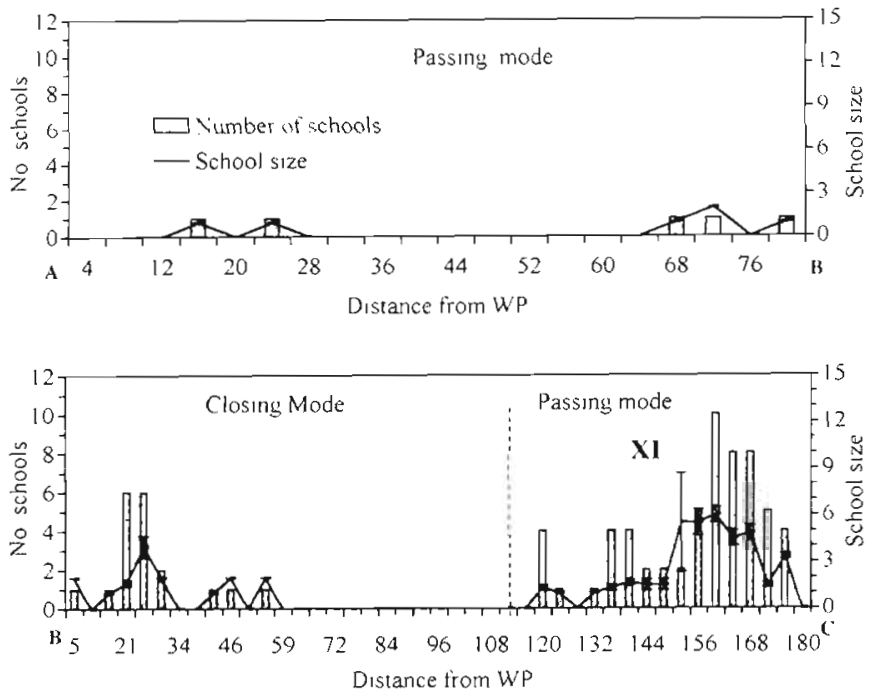

Fig. 7. Minke whale school density in Prydz Bay. Roman numerals are ID numbers of the aggregations. WP: waypoint

$\mathrm{df}=7,6$, and $5 ; \mathrm{p}<0.05)$, suggesting a random distribution in the aggregations. The indices $V / m$ and $I_{\delta}$, and mean crowding in the aggregations only (Table 2), suggest that most of the aggregations had a random distribution (values of $\mathrm{V} / \mathrm{m}$ and $I_{\delta}$ were close to 1 ).

Mean crowding ranged from 0.55 to 3.91 in the strata (Table 1) and from 1.50 to 4.24 in the aggregations (Table 2). The highest value (4.24) in the aggregations
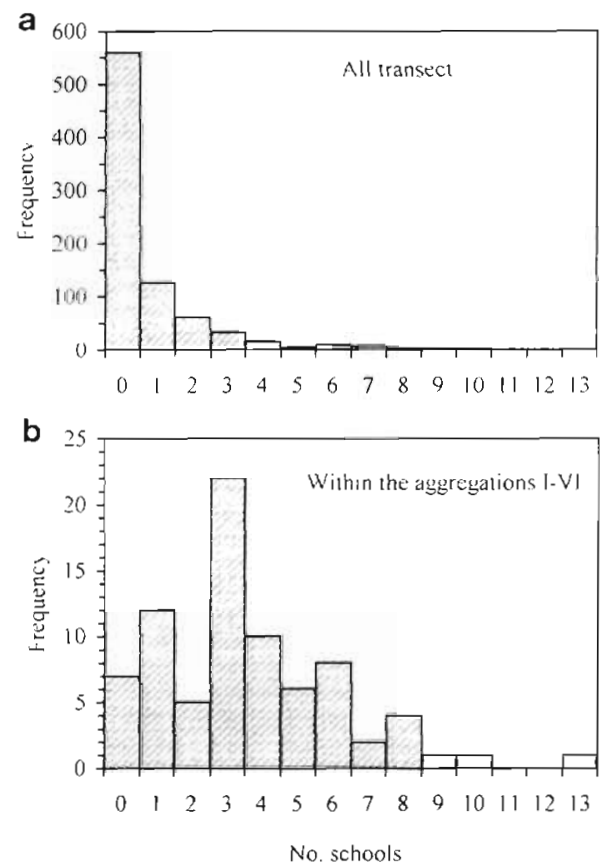

Fig. 8. Frequency distribution of number of schools (a) per unit over the whole transect and (b) per unit in the aggregations in the southern Ross Sea
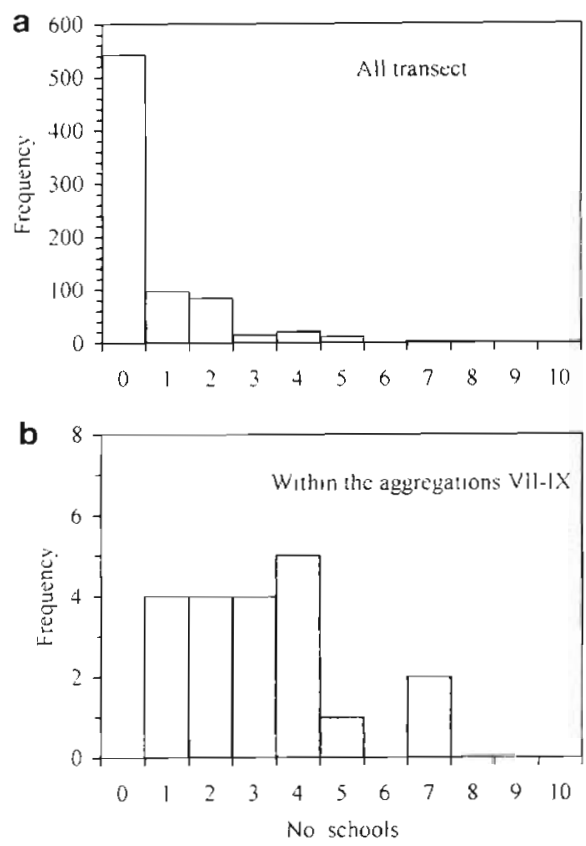

Fig. 9. Frequency distribution of number of schools (a) per unit over the whole transect and (b) per unit in the aggregations in the Weddell Sea

was observed in the Ross Sea and the lowest value (1.50) in the Weddell Sea. The mean crowding values in the aggregations were higher in the bay area (Ross Sea and Prydz Bay) than in the open waters (Weddell
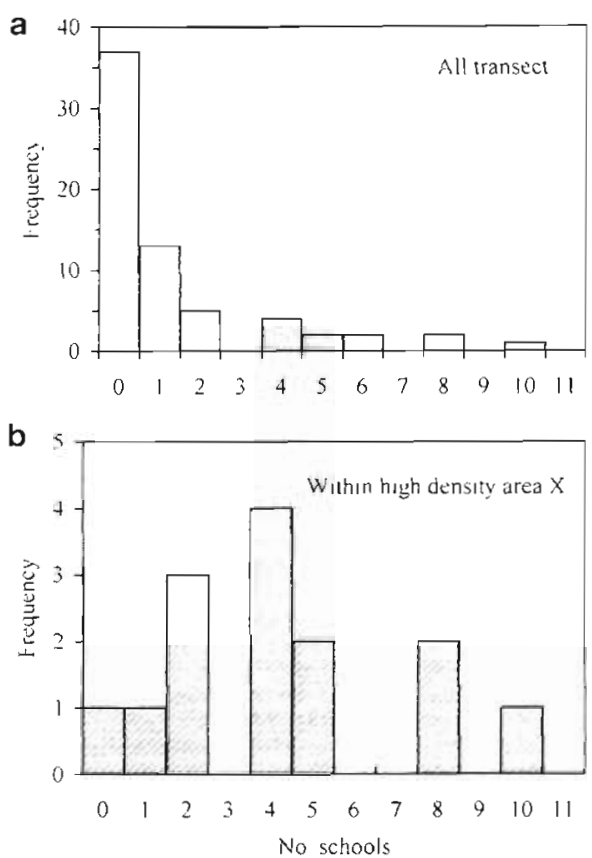

Fig. 10. Frequency distribution of number of schools (a) per unit over the whole transect and (b) per unit in the aggregations in Prydz Bay 
Sea) (Table 1), suggesting that higher clustering might occur in bays or near ice-edge areas than in offshore areas.

\section{Relationship between school density and school size}

The relationship between school density and school size in the high density area (data from closing mode surveys only) was examined (Fig. 11). Results show a clear positive correlation between school density and school size ( $p<0.01$ in all cases), indicating an increase in school size with an increase in school density. This has substantial implications in that school structure could be dynamic and could be dependent on the surrounding density of whales.

\section{DISCUSSION}

This examination of the small-scale distribution of minke whales shows that individuals tend to find more members of their own species in their immediate vicinity than would be expected in a random distribution. In general, the degree of clustering or aggregating that exists at any one moment must be a function not only of the number of whales present in a given area but also of their spatial pattern of distribution; the distribution pattern must be a function of the animal's movements, their actions toward each other when they meet, the environmental conditions, and the availability of food resources. A method for analyzing the spatial distribution pattern was developed by Iwao (1968), using the regression of mean crowding on mean density. He found that the regression of mean crowding on mean density $\left(m^{*}=\alpha+\beta m\right)$ is linear in a wide variety of situations, and that the intercept $\alpha$ and slope $\beta$ of the regression were useful as indices describing different aspects of dispersion patterns of populations of a given species. Fig. 12 shows the regression of mean crowding on mean density of schools for the whole area and the identified aggregations. The intercept $\alpha$ is zero when the distribution follows a Poisson series, and a positive value of $\alpha$ can result from an animal's preference for particularly favorable areas in the habitat. Theoretically, $\alpha$ cannot be negative, but in some cases its value obtained from extrapolation of the regression line falls below 0 . This might happen when some repulsive interaction takes place directly or indirectly between individuals. The slope $\beta$ of the regression can be regarded as an index showing the spatial pattern of habitat utilization by individuals or groups of individuals in relation to their population density. Its value is equal to unity when the distributions of individuals or schools of individu-
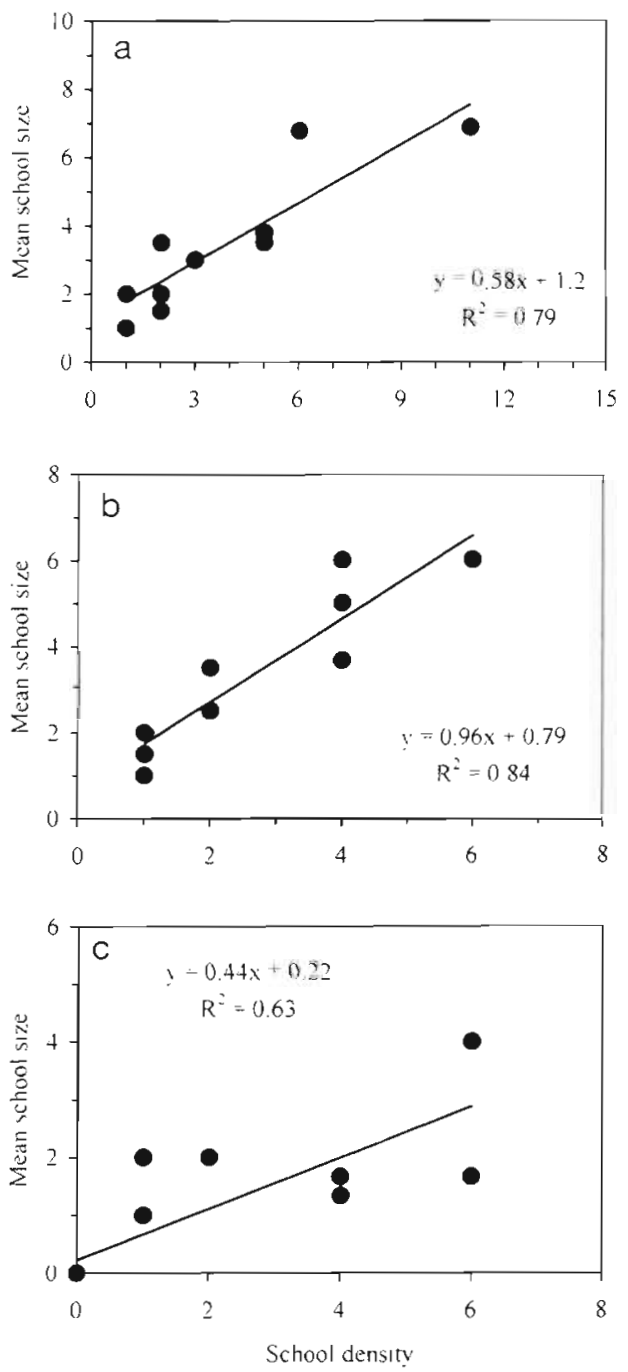

Fig. 11. Relationship between minke whale school density (no. of schools per unit) and mean school size in the aggregations (a) of the southern Ross Sea, (b) of the Weddel]. Sea, and (c) of Prydz Bay

als (with a fixed mean size) follow a Poisson series. Its value is larger than unity when the distribution is over-dispersed, and smaller than unity when the distribution is under-dispersed. Therefore, the slope $\beta$ describes the manner in which individuals or schools of individuals distribute themselves in their habitat with changing mean density.

From Fig. 12, we obtain a value of 0.16 for $\alpha$ and a value of 2.30 for $\beta$ for the whole area (using the stratabased data). Therefore, with $\alpha>0$ and $\beta>1$, the implication is that the schools are not randomly dispersed but rather that they are clustered. When the data from only the aggregations are used (Fig. 5), $\alpha$ has a negative value and $\beta$ is about 1 This suggests a relatively closeto-random distribution, with the possibility that the schools within the aggregation tend to avoid each other 


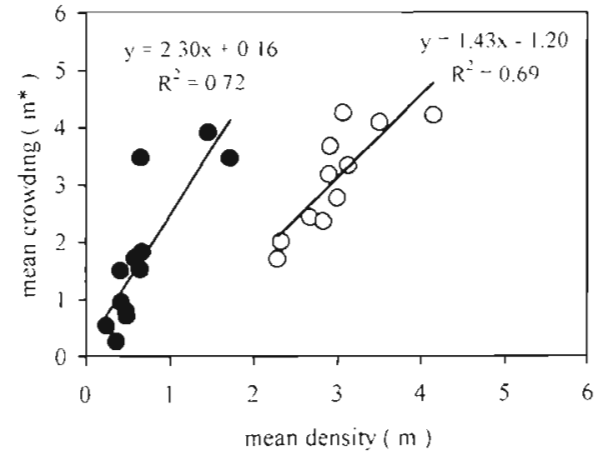

Fig. 12. Relationship between mean density and mean crowding of minke whale schools. Open circles show data from the aggregations alone (Table 2), and closed circles show data from whole area (Table 1)

$(\alpha<0)$. It must be noted that the possibility that there is some uppermost limits of mean crowding and mean density per unit area for minke whale (e.g. at around $m^{*}=3.5$ to 4.0 in Fig. 12) cannot be denied. Further investigation is needed to identify such a possible upper limit in relation to the spatial structure of whale distribution, especially the capacity per unit area.

We examined the effect of a different definition for an aggregation. There was no substantial change in the distribution pattern and the regression when an aggregation was considered to be where the density is more than 2 times the average density and where the aggregation length is larger than 2 times the average length of the areas in which whales occurred. When the definition of an aggregation was considered to be where the density is more than 4 times the average and aggregation length is more than 4 times the average. the distribution pattern was same. The $\alpha$ and $\beta$ values for the regression of mean crowding on mean density became 0.3 and 1.0, respectively, suggesting random distribution of schools in the aggregation. These suggest that the distribution pattern of schools in the aggregations (random distribution) is a robust feature.

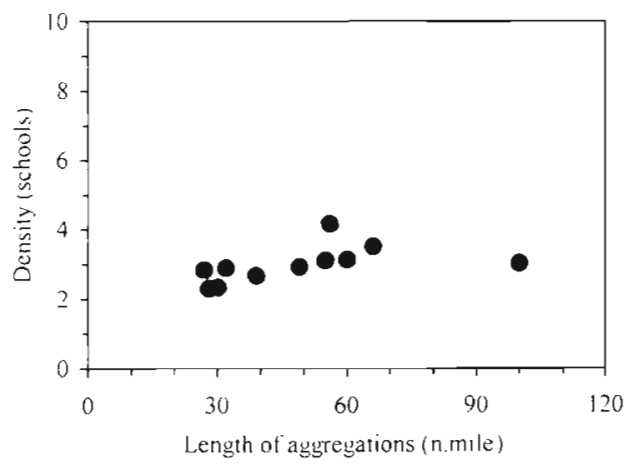

Fig. 13. Relationship between aggregation length and mean school density
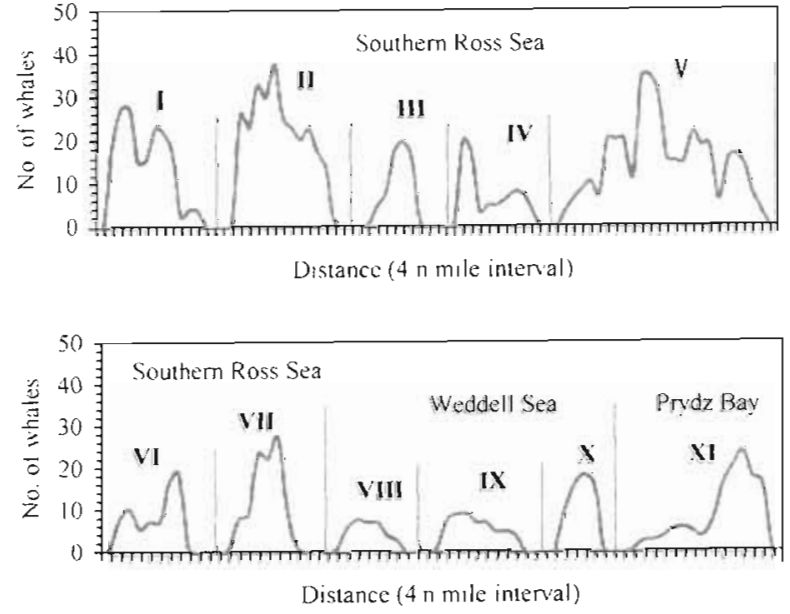

Fig. 14. Aggregation patterns observed in Ross Sea, Weddell Sea and Prydz Bay

Fig. 13 shows the relationship between mean density and length of the aggregations. Because the slope of the regression line does not differ significantly from zero $(p>0.05)$, it appears that the density in an aggregation does not change as the area of the aggregation changes. This suggests that the area of the habitat increases when abundance increases, a frequent observation for other animals (e.g. Lubina \& Levin 1988). Fig. 14 shows the distribution patterns for the aggregations (number of whales per unit). From Figs. 13 \& 14, we can generalize about the distribution patterns within aggregations in relationship to total abundance within the aggregation, as shown in Fig. 15. The implication drawn from these patterns is that when an area (feeding ground) is favorable, the density in a aggregation will increase up to a certain level. Subsequently, the area of the aggregation will expand while the density in the aggregation remains relatively stable. These results and conjectures raise several questions. One point of concern is to determine what drives these observed distributions. Are these patterns driven by

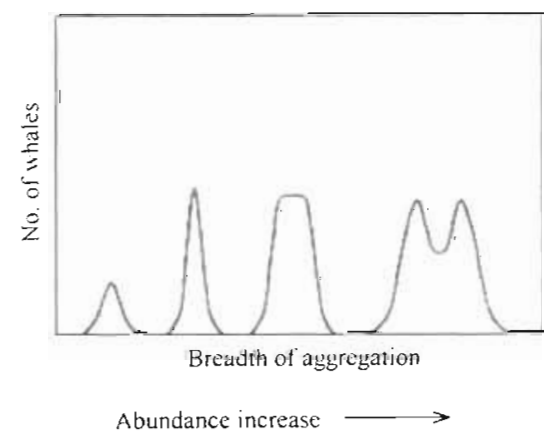

Fig. 15. Possible aggregating pattern of minke whales with relation to density and abundance 
the species' social structure or migration patterns, or other aspects independent of the environment, or are they driven by other external factors, such as food density? For example, are the dimensions of an aggregation controlled by the dimensions of a rich food source (e.g. a dense krill patch), or do the dimensions of the food source exceed the dimensions of the aggregation so that only the behavioral aspects are critical? Although extensive work has been done on the patchiness of krill distributions (for example, Higginbottom et al. 1988, Siegel \& Kalinowski 1994), the work has not simultaneously collected information about the corresponding patchiness of whale distributions. Gaining a greater understanding of these mechanisms could provide useful tools to examine and monitor a population, and particularly small-scale changes within the population. If we observe changes in the aggregations, are we seeing changes in the population? For example, suppose a general increase in the population occurs. Will there be a proportional increase in both the number of aggregations and the density within the aggregations, or will either the number of aggregations or the density within the aggregations increase first?

We have looked at the small-scale distribution of minke whales in terms of aggregations. Although we have provided some conjecture as to possible causes, the scope of this paper does not include an analysis of the relationship between biological or geophysical environments and the distribution pattern or aggregation pattern of the whales. Other work, however, does provide some tantalizing suggestions about these relationships (e.g. Reilly 1990, Ballance et al. 1997), suggesting some interesting relationships for dolphins and sea birds. In the Antarctic waters, relatively higher densities of sea birds and whale biomass were previously reported in the waters $73-74^{\circ} \mathrm{S}, 170^{\circ} \mathrm{E}-175^{\circ} \mathrm{W}$ at the continental-shelf-break front in the southern Ross Sea (Ainley 1985), where a high density of minke whales was also observed in our surveys (Waypoints between $E$ and G). In the Weddell Sea, the observed areas of high densities of minke whales are well correlated with the ocean front associated with the Weddell Gyre (Kasamatsu et al. 1998). These results still provide only a hint as to the driving forces in the smallscale distribution patterns we observed. Future investigations on relationships between environmental or biological gradients and distribution pattems should prove enlightening and useful.

\section{CONCLUSIONS}

In large aggregations, where the distribution appears to be more random or uniform than that within individual patches, and where the whale density approaches a constant value, there is an implication of optimum density. This, in turn, implies that the greater the number of whales in an aggregation, the larger the area of the aggregation. What is not understood are the mechanisms that drive the dimensions of the aggregations, or how these aggregations would respond to changes in the population. If one is able to gather information about the dynamics of the patches or aggregations in relation to total abundance, one could possibly monitor the status of the population. Even failing the use of these dynamics as a measure of population trends, a greater understanding of them will enhance our understanding of the vulnerability of standard assessment methods regarding the distribution patterns of the whales. Our understanding of the distribution patterns or aggregation patterns of cetaceans is very limited. This limitation is due-at least in part - to the difficulties of studying pelagic populations. The effort required to examine these micro-distribution patterns and the driving forces behind them would be amply rewarded not only by gaining a greater understanding of cetacean ecology but also by leading to improvement in the design of censusing methods to obtain abundance estimates with minimal variance.

Acknowledgements. We thank Ms Marianne Moon for her diligent editing of the manuscript. The authors express thanks to Dr Sharon Hedley, Research Unit for Wildlife Population Assessment, Mathematical Institute, St. Andrews, UK, and Dr Kazuhiko Fujita, Kansai Research Center, Forestry \& Forest Products Research Institute, Ministry of Agriculture, Forest and Fisheries, Japan, for their critical and useful comments and suggestions to improve the manuscript. We thank the 3 anonymous reviewers for their useful comments.

\section{LITERATURE CITED}

Ainley DG (1985) Biomass of birds and mammals in the Ross Sea. In: Siegfried WR, Condy PR, Laws RM (eds) Antarctic nutrient cycles and food webs. Springer-Verlag, Berlin, p $498-515$

Anonymous (1987) Report of the 1985/86 IWC/IDCR Southern Hemisphere minke whale assessment cruise, Area $\mathrm{V}$. Paper SC/38/Mi26 presented to the IWC Scientific Committee, May 1986. IWC secretariat

Anonymous (1988) Report of the 1986-87 IWC/IDCR Southern Hemisphere minke whale assessment cruise, Area II. Paper SC/39/Mi14 presented to the IWC Scientific Committee, June 1987. IWC secretariat

Ballance L. Pitman RL, Reilly SB (1997) Seabird community structure along a productivity gradient: importance of competition and energetic constraint. Ecology 78:1502-1518

Best PB, Butterworth DS (1980) Report of the Southern Hemisphere minke whale assessment cruise, 1978/79. Rep Int Whaling Commn 30:257-283

Best PB, Ohsumi S (1980) International Whaling Commission International Decade of Cetacean Research (IWC/IDCR) Southern minke whale assessment cruise 1978/79. Polar $\operatorname{Rec} 20: 52-57$ 
Buckland ST (1985) Perpendicular distance models for line transect sampling. Biometrics 41:177-195

Buckland ST, Anderson DR, Burnham KP, Laake JL (1993) Distance sampling. Estimating abundance of biological populations. Chapman \& Hall, London

Burnham KP, Anderson DR, Laake JL (1980) Estimation of density from line transect sampling of biological populations. Wild Monogr 44:1-202

Hiby AR, Hammond PS (1989) Survey techniques for estimating abundance of cetaceans. Rep Int Whaling Commn (Spec Issue 11):47-80

Higginbottom IR, Kerry KR, Wayte SE (1988) Hydroacoustic surveys of the distribution and abundance of krill: Prydz Bay region-FIBEX, ADBEX II and SIBEX II, MV Nella Dan. ANARE Research Notes 62, Antarctic Division, Department of the Arts, Sport, the Environment, Tourism, and Territories, Kingston, Tasmania

Iwao S (1968) A new regression method for analyzing the aggregation pattern in animal populations. Res Popul Ecol 10:1-20

Kasamatsu F, Joyce GG (1995) Current status of Odontocetes in the Antarctic. Antarct Sci 7:365-379

Kasamatsu F, Joyce GG, Ensor P, Kimura N (1998) Distribution of minke whales in the Weddell Sea in relation to the sea-ice and sea surface temperature. Bull Jpn Soc Fish Oceanogr (in press)

Kasamatsu F, Hembree D, Joyce GG, Tsunoda L, Rowlett R, Nakano $T$ (1988) Distribution of cetacean sightings in the Antarctic: results obtained from the IWC/IDCR minke whale assesment cruises, 1978/79-1983/84. Rep Int Whaling Commn 38:449-487

Kasamatsu F, Ensor P, Mermoz J, Shigemune H, Nakanishi S, Zorin A, Da Silva V, Newcomer W, Ohwada A (1989)

Editorial responsibility: Otto Kinne (Editor),

Oldendorf/Luhe, Germany
Report of the 1988/89 IWC/IDCR Southern Hemisphere minke whale assessment cruise, Area IV. Paper SC/41/SHMi7 presented to the IWC Scientific Committee meeting, May 1989. IWC secretariat

Kasamatsu F, Joyce GG, Ensor P, Mermoz J (1996) Current occurrence of baleen whales in Antarctic waters. Rep Int Whaling Commn 46:293-304

Kasamatsu F, Nishiwaki S, Ishikawa H (1995) Breeding areas and southbound migrations of southern minke whales $B a l$ aenoptera acutorostrata. Mar Ecol Prog Ser 119:1-10

Lloyd M (1967) Mean crowding. J Anim Ecol 36:1-30

Lubina JA, Levin SA (1988) The spread of a reinvading species: range expansion in the California sea otter. Am Nat 131:526-543

MacArthur RH (1955) Fluctuations of animal populations and a measure of community stability. Ecology 36:533-536

MacArthur RH (1972) Geographical ecology. Patterns in the distribution of species. Harper \& Row, New York

Mangel M, Clark CW (1988) Dynamic modeling in behavioural ecology. Princeton Univ Press, Princeton, NJ

Morishita M (1959) Measuring of dispersion of individuals and analysis of the distributional patterns. Mem Fac Sci Kyushu Univ Ser E 2:215-235

Pielou EC (1969) An introduction to mathematical ecology. Wiley-Interscience, New York

Reilly SB (1990) Seasonal changes in distribution and habitat differences among dolphins in the eastern tropical Pacific. Mar Ecol Prog Ser 66:1-11

Siegel V, Kalinowski J (1994) Krill demography and small-scale processes: a review. In: El-Sayed SZ (ed) Southern Ocean ecology. Cambridge Univ Press, Cambridge, p 145-163

Taylor LR (1961) Aggregation, variance and mean. Nature 189:732-735

Submitted: February 24, 1998; Accepted: April 3, 1998

Proofs received from author(s): June 9, 1998 